\title{
Discussion
}

\section{REJOINDER TO SOAMES}

\author{
Christopher Pincock \\ Philosophy / Purdue U. \\ West Lafayette, IN 47907, USA \\ PINCOCK@PURDUE.EDU
}

$M$

y goal in reviewing Soames' book was to help readers of this journal eval-

uate his contribution to the history of analytic philosophy, with a special

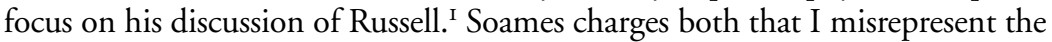
contents of his book and that I make mistakes in the interpretation of various aspects of Russell's philosophy. If I had committed any errors of the former sort, I would certainly apologize and thank Soames for bringing such mistakes to my attention. After explaining why I do not believe I have misrepresented the contents of his book, I will turn to the one substantive issue that he raises in his reply, namely the need for unperceived sense-data in Russell's external world program. While disagreement here is more understandable, nothing Soames says in his book or in his reply has led me to revise my original remarks.

My review began with a one-page summary of Soames' $890-$ page book. I said that "Moore, and nearly every other figure that Soames discusses, is [said to be] guilty of confusing necessity, analyticity and apriority" and in the next paragraph mentioned "Moore's views on ethics" and "Russell's conception of analysis" ("Reply", p. I68). Soames replies: "Not so. Although I do show that such conflation had negative consequences for the views of several philosophers, Moore and Russell are not among them" (p. I72). I could have added more page references to my discussion. On Moore, after a long list of twelve "fundamental methodological notions" which include analysis, analyticity and necessity, Soames claims that "unclarity about these fundamental methodological notions eviscerated his most important meta-ethical conclusions" (I: 74). For

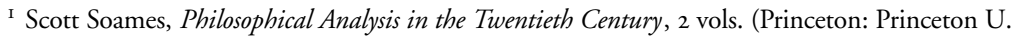
P., 2003). Christopher Pincock, "History of Philosophical Analysis", Russell, n.s. 25 (winter 200506): 167-7I. Scott Soames, "Reply to Pincock", Russell, n.s. 25 (winter 2005-06): 172-7. References preceded by "I:" or "2:" refer to the volumes of Soames' book. Other unlabelled references in the text will be either to my review or to Soames' reply. 
Russell, Soames notes that Russell's "view that ordinary proper names mean the same as descriptions associated with them by speakers ... was ultimately shown to be deeply problematic by Saul Kripke in Naming and Necessity" (I: I23). A reference is then made to Soames' discussion of Kripke in Volume 2 where Soames explains how Kripke's “modal argument" undermined Russell's approach (2: 337 ).

Soames also complains that I object to his "characterization of Russellian propositions as complexes of properties and objects whose structure mirrors the logical forms of sentences that express them" (p. 177). What I said was that it was "extremely misleading" to say that (quoting Soames again) "propositions constitute the information encoded by sentences ... [and of] the information encoded by a sentence (in a logically perfect language) as a complex entity the structure of which mirrors the structure of sentences" (p. I69 and I: I04-5). So, Soames did not say that propositions are "complexes of properties and objects" and if he had said this I would not have objected. Soames goes on to use a settheoretic construction to explain exactly what propositions are. But there is a big difference between a set-theoretic construction and a complex of the sort Russell had in mind, and a reader of Soames would have no awareness of the gap. That is, she is likely to be misled. ${ }^{2}$

Finally, Soames says that "Pincock foolishly speculates" (p. I77) in ascribing confusion to him about the relevance of Gödel's incompleteness theorems to Principia Mathematica. Now, when a philosopher gives an argument described as the "final nail in the coffin" (I: I57), and this argument depends on a tacit assumption, I submit that it is far from foolish to think that the philosopher believes that this assumption is correct. This is, after all, just the methodology that Soames employs when he reconstructs the commitments of the philosophers that he talks about. And, in this case at least, Soames agrees with me that "the comment about Gödel he highlights does require more explanation" (p. I77). To add "which it will receive in the second edition" (p. I77) is to grant that my remark was not foolish.

Setting aside the charges that I misrepresented Soames' views in my review, I turn to the errors that I am supposed to have made about Russell's conception of sense-data in Our Knowledge. First, some preliminary points. I did not derive my criticisms from Nicholas Griffin's review, and if I had, I would have cited that review. Also, Soames complains that it is unclear what I mean when I say that he ascribes "some form of latent verificationism" to Russell (p. I73). But he goes on to give just the remark I had in mind: two principles that Soames

\footnotetext{
${ }^{2}$ Another question she might have is how a proposition of $\mathrm{I}$ : Chap. 5 relates to a fact of $\mathrm{I}$ : Chap. 8 , which is also called a "complex entity" (I: I86) without much further explanation.
} 
extracts from Russell "constitute a historical precursor to a famous philosophical principle-the 'Verifiability Criterion of Meaning'” (I: I72). Finally, Soames now admits that he was not aware of the differences between the 19I4 (OKEW) and $1926\left(\mathrm{OKEW}_{2}\right)$ editions of Our Knowledge (p. 172 n.3), but relies on both editions in his reply and takes Russell's remark in the preface to the 1929 $\left(O K E W_{3}\right)$ edition as evidence that the changes "made no difference to his overall argument" on sense-data (p. I74 n.6). The first edition of Our Knowledge was always my focus. The 1927 book, The Analysis of Matter, which Soames does not cite, is the best indicator of Russell's views on these questions late in the 'twenties, and I will summarize the shift between I9I4 and I927 below.

Russell's most extensive discussion of sense-data in this period occurs in the opening chapters of Theory of Knowledge (Papers 7). ${ }^{3}$ As these writings make clear, a sensation for Russell is an event that involves a subject standing in a relation of acquaintance to a particular, which is labelled a "sense-datum" (Papers 7: 66). This is the so-called act-object conception of sensation, which is distinguished both from the more traditional act-content-object approach and the object-only approach of neutral monism. Russell repeatedly argued against the act-content-object conception, often focusing on the problematic nature of the essentially mental content presupposed by this theory. In contrast, a sensation is mental for Russell only because it involves the mental relation of acquaintance. Sense-data themselves are not mental (Papers 7: 35), and are sometimes called "physical" ("Letter on Sense-Data", Papers 8: 8). Russell's later development, then, can be fairly summarized by saying that he shifted from an act-object conception of sensation to an object-only conception. After the shift the only particulars in Russell's metaphysics were events, which include what were previously dubbed "sensations" and are now often called "percepts". At this stage, whether or not an event is mental or physical is not an intrinsic feature of that event, but obtains in virtue of the sorts of relations that the event stands in. Exactly when Russell made this shift is difficult to pinpoint. The interpretative question mainly turns on the status of images in The Analysis of Mind.

With this background in mind, we can distinguish several claims which Soames makes about sense-data. (I). "[T] he properties Russell assigns to sensibilia are the familiar ones that allow them to play their standard epistemological role" ("Reply", p. I75). (II). "Russell is not claiming that some of the truths of physics-apart from purely conceptual truths - are known independent of verification" (p. I73). (III). Russell grants that it is epistemically

3 While the manuscript was abandoned in 1913, the first six chapters were published in The Monist in 1914, and the first three chapters were reprinted under the heading "The Nature of Acquaintance" in the influential 1956 collection Logic and Knowledge. 
problematic for him to invoke unperceived sense-data in his logical constructions. For example, he says that it is "probable" that "the immediate objects of sense [sense-data] depend for their existence upon physiological conditions in ourselves, and that, for example, the coloured surfaces which we see cease to exist when we shut our eyes" (p. 174 and $O K E W$, p. 64), which suggests that sense-data exist only where an appropriately constituted subject happens to be. (IV). "The end result is a reconstruction of all knowledge of material objects in terms of the actual sense experiences of arbitrary agents, plus experiences they would have in various conditions. None of this presupposes unperceived sensedata" (p. 175).

(I). Among the properties that Soames ascribes to perceived Russellian sensedata is transparency: when we are acquainted with sense-data, they are "known, with essentially Cartesian certainty, to have the properties they appear to have" (p. 175). By contrast, consider Russell's claim that "two sense-data may be, and must sometimes be, really different when we cannot perceive any difference between them" (OKEW, p. I4I) ${ }^{4}$ This is a continuation of Russell's discussion of sense-data in Theory of Knowledge (Papers 7: 9, I27). This aspect of Russell is significant as it shows that Russell is willing to posit perceived sense-data that go beyond what a foundationalist empiricist project would usually countenance.

(II). But what, then, guides or constrains what sense-data we should posit? The Our Knowledge lectures are meant to illustrate a new "scientific method in philosophy", and in the last lecture Russell outlines what this method is:

We start from a body of common knowledge, which constitutes our data. On examination, the data are found to be complex, rather vague, and largely interdependent logically. By analysis we reduce them to propositions which are as nearly as possible simple and precise, and we arrange them in deductive chains, in which a certain number of initial propositions form a logical guarantee for all the rest. These initial propositions are premisses for the body of knowledge in question. Premisses are thus quite different from data — they are simpler, more precise, and less infected with logical redundancy.

(OKEW, p. 2II $\left.{ }^{5}\right)$

As the next page makes clear, the premisses are often open to doubt, including the premisses involved in the constructions canvassed in Lecture 3: "In our third

${ }^{4}$ See also $O K E W$, p. I49, which explicitly relies on the discussion of instants which I will introduce below.

5 See also the discussion from $O K E W$, pp. 65-73. Strangely, Soames allows Russell something like this more sophisticated account of justification in his chapter on logicism (I: I60), but fails to see the relevance of this to his discussion of $O K E W$. 
lecture, for example, we saw that the part of physics which depends upon testimony, and thus upon the existence of other minds than our own, does not seem so certain as the part which depends exclusively upon our own sense-data and the laws of logic" (OKEW, p. 2I2). This shows that some of the premisses involved in clarifying an individual's knowledge of the truths of physics must be known independently of their verification in terms of that individual's sensedata. These premisses are not reasonably classified as "purely conceptual truths". Russell's attempts to isolate such premisses begin in places like The Problems of Philosophy (Chap. XI) and extend into his late philosophy, e.g. Human Knowledge: Its Scope and Limits (especially Part 6).

(III). I agree with Soames that Russell would prefer, all other things being equal, not to posit unperceived sense-data. I think we also agree that it was an option for Russell to invoke unperceived sense-data, although it would come with certain costs for his epistemic project. So the central issues between us are what factors are relevant in making such posits and whether Russell makes them in Our Knowledge. Given my discussion of (II), it should be clear what these costs would be. If Russell invoked unperceived sense-data, then he would need a premiss summarizing this commitment and this premiss would be less certain than one that talked only about one's own sense-data, or about perceived sensedata across agents. I believe, however, that this is a cost that Russell is willing to pay if it is the only way of recovering our original knowledge of physics. Here I appear to disagree with Soames, who thinks that even assuming the actual sense-data of others deprives Russell's proposal of its epistemic significance (I: I80). But the fact that Russell does, as Soames admits, invoke the actual sense-data of others suggests that Russell's goals are more modest than those Soames attributes to Russell.

In assessing Soames' quotation in support of (III) it is essential that we notice that Russell is talking about the "physiological conditions" of our bodies, and not anything connected to the self or the mind. The point of Russell's discussion here is that our sensory apparatus, including our brain, is akin to a medium that affects the sort of sense-data that a subject will have in a given context. As he says later, "Physiological changes also alter the appearances of things. If we assume the world of common sense, all these changes, including those attributed to physiological causes, are changes in the intervening medium" (OKEW, p. 78). In an attempt to handle the problem of intervening media Russell then begins a discussion of what is perceived when we wear blue spectacles. So, Soames' passage is irrelevant to the question of whether or not Russell invokes unperceived sense-data in his logical constructions. All he is saying here is that the sense-data we do perceive depends on the state of our body, just as much as if there were an opaque surface in front of us (cf. Papers 8: 87). 
(Iv). On Soames' interpretation, Russell settles on logical constructions that involve only perceived sense-data of existing subjects as well as "experiences they would have in various conditions". These experiences are not unperceived sense-data but instead grounded in counterfactual conditionals like "If I were to have sensations called 'walking around the table,' then my visual sense data would gradually change in a certain continuous way ..." (I: I7O), which Russell must further specify. By contrast, I take Russell's considered proposal to be given in Our Knowledge, pages 87-93, where he mentions Leibniz (OKEW, p. 87 ) and which he refers to as a "hypothetical construction". This discussion follows an unsuccessful attempt to reconstruct our knowledge of the external world in terms of the "hard data" of an individual's sense-data and the truths of logic (OKEW, pp. 72-83). Many of the passages that Soames relies on pertain to these pages. For example, Soames is impressed by Russell's claim that "in so far as physics or common sense is verifiable, it must be capable of interpretation in terms of actual [perceived] sense-data alone" ("Reply", pp. 175-6 and $O K E W$, p. 8I). But after reviewing what is achievable by these means Russell concludes that this "will not carry us very far towards the establishment of a whole science" (OKEW, p. 83). By contrast, the Leibnizian hypothetical construction

... shows that the account of the world given by common sense and physical science can be interpreted in a way which is logically unobjectionable, and finds a place for all the data, both hard and soft. It is this hypothetical construction, with its reconciliation of psychology and physics, which is the chief outcome of our discussion. Probably the construction is only in part necessary as an initial assumption, and can be obtained from more slender materials by the logical methods of which we shall have an example in the definitions of points, instants, and particles; but $I$ do not yet know to what lengths this diminution in our initial assumptions can be carried. $\quad$ (OKEW, p. 97; my emphasis)

Crucially, Russell's hypothetical construction involves not only the perceived sense-data of subjects, but also unperceived sense-data:

Hence we may suppose, in spite of the differences between the different worlds [of two subjects], that each exists entire exactly as it is perceived, and might be exactly as it is even if it were not perceived. We may further suppose that there are an infinite number of such worlds which are in fact unperceived. If two men are sitting in a room, two somewhat similar worlds are perceived by them; if a third man enters and sits between them, a third world, intermediate between the two previous worlds, begins to be perceived. It is true that we cannot reasonably suppose just this world to have existed before, because it is conditioned by the sense-organs, nerves and brain of the newly arrived man; but we can reasonably suppose that some aspect of the universe existed from that point of view, though no one was perceiving it.

(OKEW, pp. 87-8)

The need for such unoccupied "perspectives" is clear from Russell's discussion. It is only if we assume perspectives in addition to the private worlds occupied 
by subjects that it is possible to place the occupied perspectives in a public perspective space.

Soames' only claim about this construction is that his own preferred interpretation of Russell in terms of counterfactual conditionals

$\ldots$ is in all essential respects equivalent to the analysis of material object statements in terms of statements about the sense data found in perspectives occupied by actual observers plus statements about the sense data found in perspectives that no one actually occupies (at least at the moment), but which could be occupied if certain conditions were fulfilled.

This puts Soames in the awkward position of assailing me for defending a position that he says is equivalent to his own. On my proposal, of course, there is an enormous difference between positing unoccupied perspectives and invoking counterfactual conditionals. That Soames does not see the significance of this difference is even more evidence that he does not understand what is going on in Our Knowledge.

Soames finds additional evidence in favour of his counterfactual conditional proposal in Lecture 4. Here indeed we do see, again, Russell trying to get by without unperceived sense-data, but a consideration of the details of his constructions shows that he is not successful. The passages that Soames places such emphasis on in Our Knowledge, pages III-I2, occur in the course of Russell's proposed definition of things or matter as "those series of aspects which obey the laws of physics" (OKEW, p. IIo). If, as in the beginning of Lecture 3, "physics is to consist wholly of propositions known to be true, or at least capable of being proved or disproved", then we must show all unperceived sense-data are "capable of being exhibited as logical functions of [actual] sensedata" (p. 176 and $O K E W$, p. III). But does Russell show this? For two reasons, he does not. First, he concludes his discussion of matter, spatial points and temporal instants by saying that his discussion

... is intended merely to show the kind of way in which, given a world with the kind of properties that psychologists find in the world of sense, it may be possible, by means of purely logical constructions, to make it amenable to mathematical treatment by defining series or classes of sense-data which can be called respectively particles, points, and instants.

(OKEW, p. I22; my emphasis)

Second, the constructions themselves do not dispense with unperceived sensedata. On the contrary, the constructions presuppose unperceived sense-data precisely where they were needed in the construction in Lecture 3, i.e. in placing occupied perspectives at appropriate locations in the public space of perspectives. 
Consider, for example, Russell's discussion of instants. ${ }^{6}$ Russell clearly states the assumptions that he must make about events, or the sensations that comprise a subject's experience, in order to construct temporal instants (OKEW, p. I2O n.I). These assumptions are extremely strong and include a kind of density for events: "If one event wholly precedes another, there is an event wholly after the one and simultaneous with something wholly before the other" (ibid.). This assumption, and others that Russell makes, require that the events of our experience manifest connections that we are not aware of. For such constructions to work, Russell must deny the transparency that we discussed earlier under (I).

However, such denials are only the first step in completing a construction of temporal instants adequate for physics. For as Russell is all too aware, the instants constructed so far are instants only for the "local time" (OKEW, p. I03) of each subject and "The correlation of the times of different private worlds so as to produce the one all-embracing time of physics is a more difficult matter" (OKEW, p. I2I). What Russell is worrying about are the problems associated with interpreting the special theory of relativity. Even if we succeed in constructing and ordering the instants of time for each private world, there is still the difficult issue of how to identify which instants occur at the same physical time. Notoriously, special relativity calls this into question because a transformation from one inertial frame of reference to another can alter some of these temporal relations. ${ }^{7}$

All that Russell tells us about such issues here is that "The correlation of different private times is regulated by the desire to secure the simplest possible statement of the laws of physics, and thus raises rather complicated technical problems" (OKEW, p. I22). Until these problems are resolved, the hypothetical construction canvassed in Lecture 3, with its unoccupied perspectives, stands as the only option Russell presents for interpreting our knowledge of physics. But in the important paper "The Relation of Sense-Data to Physics", written early in 1914, Russell takes another pass at correlating instants across perspectives, and explains how this underlies his definition of matter:

The general principle is that the appearances, in different perspectives, which are to be grouped together as constituting what a certain thing is at a certain moment, are not to be all regarded as being at that moment. On the contrary they spread outward from the thing with various velocities [my emphasis] according to the nature of the appearances. Since no direct means exist of correlating the time in one biography with the time in

${ }^{6}$ A helpful paper is C. A. Anderson, "Russell on Order in Time", in C. W. Savage and C. A. Anderson, eds., Rereading Russell, Minnesota Studies in the Philosophy of Science, Vol. I2 (Minneapolis: U. of Minnesota P., 1989), pp. 249-63.

7 See, e.g., Michael Friedman, Foundations of Space-Time Theories (Princeton: Princeton U. P., I983), \$IV.7. 
another, this temporal grouping of the appearances belonging to a given thing at a given moment is in part conventional. Its motive is partly to secure the verification of such maxims as that events which are exactly simultaneous with the same event are exactly simultaneous with one another, partly to secure convenience in the formulation of causal laws.

("The Relation of Sense-Data to Physics", Papers 8: 5-26 [at I9])

As Russell here recognizes, in order to relate the time at which I perceive a flash of lightning with when someone else perceives it, there must be a continuous chain of events in the public, perspective space radiating outwards from the location of the lightning event in public space. This chain involves regions where there are no subjects. I conclude that Russell must posit "biographies" at each place in the public space, and that these biographies are occupied by unperceived sense-data of equal complexity to the perceived sense-data of subjects, just as in his original hypothetical construction. Without this, he will not be able to interpret the laws of physics that form part of the data he is intent on recovering.

Russell is quite frank about the costs of such constructions in "The Relation of Sense-Data to Physics", writing, for example, that

I should hope that, with further elaboration, the part played by unperceived "sensibilia" could be indefinitely diminished, probably by invoking the history of a "thing" to eke out the inferences derivable from its momentary appearance.

(Papers 8: 26)

Such hopes were never fulfilled. Instead, the even more significant changes forced by the general theory of relativity heightened the need for unperceived sense-data or, more properly, events that are not percepts. The Analysis of Matter adopts this picture under the label of a causal theory of perception, and contains Russell's most detailed logical constructions of spatio-temporal points ( $A M a$, Chaps. 28, 29). After considering a construction lacking unperceived sense-data, or in his new terminology, events that are not percepts, Russell concludes that "it has no positive grounds in its favour" ( $A M a, \mathrm{p} .2 \mathrm{I} 4)$ and resolves that he "shall assume henceforth not only that there are percepts which I do not perceive, connected with other people's bodies, but also that there are events causally connected with percepts, as to which we do not know whether they are perceived or not" (AMa, pp. 215-16). ${ }^{8}$

Now, Soames may think that "the details of this construction are not impor-

${ }^{8}$ See also The Analysis of Matter, p. 399, where this commitment is reaffirmed. This discussion from 1927 clearly undermines Soames' thought (pp. 174-5) that Russell's remarks in the revised edition in 1926 of Our Knowledge, p. 83, support his interpretation. In fact, Soames elides the reference, "in The Analysis of Mind (e.g. p. I4I ff.)", where Russell explains his shift to neutral monism. 
tant" (I: I7I) because in the end Russell must only be invoking conditionals when he talks about unperceived sense-data. I have two replies to this. First, Russell would not allow conditionals that were not grounded in the existence of something actual. As he says in Theory of Knowledge, "It may be laid down generally that possibility always marks insufficient analysis: when analysis is completed, only the actual can be relevant, for the simple reason that there is only the actual, and that the merely possible is nothing" (Papers 7: 27). Second, the conditionals that Soames has in mind here would be "calculable" only using the laws of physics, and it is precisely Russell's constructions of space, time and matter that must be place for these mathematical laws to be so applicable. Soames complains about Russell's supposed assumption of these conditionals (I: I80), but fails to see that positing unperceived sense-data is part of Russell's sophisticated strategy for making such an appeal superfluous (see also I: 192).

I conclude that Soames' interpretation of sense-data in Russell's logical constructions is flawed. When we look at the details of what Russell says and what he does, we get a more accurate picture of what he was trying to do and what he was willing to assume in order to achieve his goals. Would I insist that all of these technicalities appear in an introductory discussion of Russell's work? Of course not. But I would hope that the writer of an introductory book would be aware of them, and would help students to see the limitations of his own introductory treatment. 